\title{
The use of dialkyl carbonates for safe and highly selective alkylations of methylene-active compounds. A process without waste production
}

\author{
Andrea Bomben, Maurizio Selva, Pietro Tundo * \\ Dipartimento di Scienze Ambientali dell'Universita' di Venezia, Calle Larga S. Marta 2137, 30123, \\ Venezia, Italia \\ (Received November 15, 1995)
}

\begin{abstract}
The non-toxic compound dimethyl carbonate (DMC) can be used as a methylating and a methoxycarbonylating agent in place of methyl chloride and phosgene, respectively. We report here that DMC and other dialkyl carbonates (DAlkCs: dimethyl, diethyl and dibenzyl carbonates) allow very selective alkylations of a variety of $\mathrm{CH}_{2}$-acidic compounds. Both arylacetonitriles and alkyl arylacetates react with DAlkCs to yield the mono-C-alkylated derivatives ( $\alpha$-alkyl- $\alpha$-arylacetonitriles and alkyl $\alpha$-alkyl- $\alpha$-arylacetates) with a selectivity of up to $99 \%$, at complete conversion. Likewise, the mono-Cmethylation by DMC proceeds selectively also on (aryloxy)acetonitriles and methyl (aryloxy)acetates. The reactions are carried out at temperature of $180-220^{\circ} \mathrm{C}$ in the presence of weak bases (usually $\mathrm{K}_{2} \mathrm{CO}_{3}$ ); under such conditions, DAlkCs efficiently replace the common and very toxic alkylating agents (dialkyl sulfates and alkyl halides). In addition to the high selectivity obtained and the intrinsic safety of the dialkyl carbonates, the reported reactions give rise to neither organic nor inorganic waste products.
\end{abstract}

\section{Introduction}

The direct monoalkylation of methylene-active compounds by common alkylating agents (alkyl halides and dialkyl sulfates) is generally not feasible as a one-step process because of the formation of sizable amounts of dialkyl derivatives ${ }^{1}$, especially when a reactive alkylating agent (e.g. methyl, ethyl, and benzyl halide) is involved ${ }^{2,3}$. Moreover, such an atkylation is of considerable environmental concern, as not only are alkyl halides and dialkyl sulfates highly toxic reagents, but also a stoichiometric quantity of inorganic salt has to be disposed of as the reaction waste. Nevertheless, the reaction has been widely explored since it can yield products of interest. For example, 2-arylpropionitriles $\mathrm{ArCH}\left(\mathrm{C}_{4}{ }_{3}\right) \mathrm{CN}$ (1) and methyl 2-arylpropionates $\mathrm{ArCH}\left(\mathrm{CH}_{3}\right) \mathrm{COOCH}_{3}$ (2) (obtained by the methylation of arylacetonitriles and methyl arylacetates, respectively) are intermediates for the synthesis of 2-arylpropionic acids, well-known as non-steroidal analgesics ${ }^{4}$. Likewise, 2-(aryloxy)propionic acid derivatives [ArOCH$\left(\mathrm{CH}_{3}\right) \mathrm{X} ; \mathrm{X}=\mathrm{CN}(3) ; \mathrm{X}=\mathrm{COOCH}_{3}$ (4)] are precursors for both biologically active derivatives ${ }^{5-7}$ and plant growth regulators ${ }^{8-10}$.

In that sense, the use of the non-toxic dialkyl carbonates [DAlkCs: dimethyl (DMC), diethyl (DEC), and dibenzyl (DBzlC) carbonates] as alkylating agents, is particularly profitable $^{11 a, b, 12}$. We report here that at high temperatures ( $\geq$ $180^{\circ} \mathrm{C}$ ), in the presence of a weak base (usually an alkaline carbonate), DAlkCs allow very selective batchwise and continuous-flow monoalkylation of both aryl- and (aryloxy)acetic acid derivatives where typical monoalkylation selectivities are up to $99 \%$, at complete substrate conversion (Eqn. 1) ${ }^{13-16}$. Besides the non-toxicity of DAlkCs, these alkylation reactions are intrinsically environmentally benign in character, since wastes are totally absent and the co-product alcohol can be recycled.

$$
\begin{aligned}
& \mathrm{YCH} \mathrm{CH}_{2} \mathrm{X}+\mathrm{ROCOOR} \stackrel{\text { base }}{\longrightarrow} \mathrm{YCH}(\mathrm{R}) \mathrm{X}+\mathrm{ROH}+\mathrm{CO}_{2} \\
& \mathrm{Y}=\mathrm{Ar}, \mathrm{ArO} ; \mathrm{X}=\mathrm{CN}, \mathrm{COOR} ; \mathrm{R}=\mathrm{CH}_{3}, \mathrm{CH}_{2} \mathrm{CH}_{3}, \mathrm{PhCH}_{2}
\end{aligned}
$$

\section{Reactions of dialkyl carbonates (DAlkCs)}

Dimethyl carbonate (DMC), currently prepared by the oxidative carbonylation of methanol ${ }^{17}$, is the simplest of the class of dialkyl carbonates. Its higher homologues can be synthesised by the transesterification of DMC with the appropriate alcohol (Eqn. 2) ${ }^{16,18,19}$.

$$
\begin{aligned}
& \mathrm{CH}_{3} \mathrm{OH} \underset{\mathrm{Cu} \text { salts }}{\stackrel{\mathrm{CO}, \mathrm{O}_{2}}{\longrightarrow}} \mathrm{CH}_{3} \mathrm{O}_{\mathrm{OCH}_{3}}^{\stackrel{\mathrm{O}}{\Perp}} \\
& \text { DMC }
\end{aligned}
$$

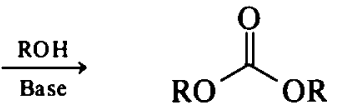

$$
\begin{aligned}
& \mathrm{R}=\mathrm{C}_{n} \mathrm{H}_{2 n+1}(n>2)
\end{aligned}
$$

In general, depending upon the reaction temperature, the reaction of DAlkCs with nucleophiles may follow two pathways where the carbonates may behave as alkoxycarbonylating or as alkylating agents. As an example, DMC is a methoxycarbonylating agent when used at its reflux temperature $\left(90^{\circ} \mathrm{C} \text {, Eqn. } 3\right)^{20}$; while it becomes an excellent methylating agent if high reaction temperature $\left(\geq 160^{\circ} \mathrm{C}\right)$ are involved (Eqn. 4) $)^{11,12,14}$. Both the reactions occur in the pres- 
Table I Methylation reactions carried out using dimethyl carbonate as the methylating agent under GL-PTC conditions ${ }^{\text {a }}$.

\begin{tabular}{|c|c|c|c|c|}
\hline Entry & Substrate & $\begin{array}{c}\text { Catalytic } \\
\text { bed }\end{array}$ & $\begin{array}{c}\text { Conversion } \\
(\%)\end{array}$ & $\begin{array}{l}\text { Products } \\
\text { (\% by GC) }\end{array}$ \\
\hline $\begin{array}{l}2 \\
3 \\
4\end{array}$ & 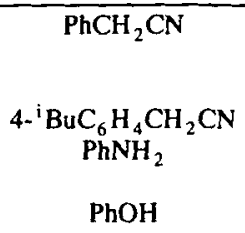 & $\begin{array}{c}\text { Corundum } \\
5 \% \mathrm{~K}_{2} \mathrm{CO}_{3} \\
5 \% \text { PEG } 6000 \\
5 \% \text { PEG } 6000 \\
\mathrm{~K}_{2} \mathrm{CO}_{3}{ }^{d} \\
5 \% \text { PEG } 6000 \\
5 \% \text { PEG } 6000\end{array}$ & $\begin{array}{r}98 \\
95 \\
\\
46 \\
100\end{array}$ & 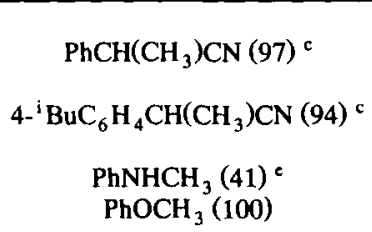 \\
\hline
\end{tabular}

${ }^{a}$ All reactions were carried out over a $100-\mathrm{g}$ catalytic bed at $180^{\circ} \mathrm{C}$ and atmospheric pressure. The liquid mixture of DMC and substrate (in a $4 / 1$ molar ratio) was sent into the reactor at flow rates of 8.0 and $24.0 \mathrm{ml} / \mathrm{h}$ for entries 1,2 and 3,4 , respectively. ${ }^{b}$ Steady-state conversions (by GC) are reported.

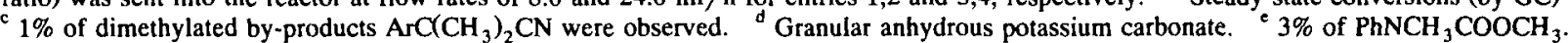

ence of bases: sodium alkoxides (Eqn. 3) and alkaline carbonates (Eqn. 4) are used. At high temperature, the alkylation reaction reaction prevails over the alkoxycarbonylation, the former not being an equilibrium reaction.

$$
\begin{aligned}
& \mathrm{YH}+\mathrm{CH}_{3} \mathrm{OCOOCH}_{3} \underset{\mathrm{T}=90^{\circ} \mathrm{C}}{\stackrel{\text { Base }}{\longrightarrow}} \mathrm{YCOOCH}_{3}+\mathrm{CH}_{3} \mathrm{OH} \\
& \mathrm{YH}+\mathrm{CH}_{3} \mathrm{OCOOCH}_{3} \frac{\text { Base }}{\mathrm{T}>160^{\circ} \mathrm{C}} \mathrm{YCH}_{3}+\mathrm{CH}_{3} \mathrm{OH}+\mathrm{CO}_{2}
\end{aligned}
$$

\section{The alkylations by dialkyl carbonates (DAlkCs)}

In the case of alkylations by the light DAlkCs (DMC and $\mathrm{DEC}$; b.p. 90 and $128^{\circ} \mathrm{C}$, respectively), the need for high reaction temperatures requires appropriate synthetic methodologies for performing the reactions under both continuousflow and batch conditions.

Continuous-flow alkylations by DAlkCs are carried out using the GL-PTC (gas-liquid phase-transfer catalysis) technique ${ }^{11,12,21}$. In a typical configuration, a liquid mixture of the reagents is sent continuously to a simple cylindrical column (plug-flow reactor) fitted with a solid-supported phase-transfer (PT) catalyst and heated at the reaction temperature. The mixture vaporizes and the reaction occurs through a continuous transfer of both the reagents and the products between the gas and the liquid catalytic phases. Gaseous products are continuously collected at the outlet of the reactor by a condenser.

Table I gives the results of some methylations by DMC performed under GL-PTC conditions. The catalytic beds con- sist of polyethylene glycol (PEG) 6000 supported on corundum $\left(\alpha-\mathrm{Al}_{2} \mathrm{O}_{3}\right)$ with $5 \%$ of $\mathrm{K}_{2} \mathrm{CO}_{3}$ as co-catalyst (entries 1,2 ), or directly on granular $\mathrm{K}_{2} \mathrm{CO}_{3}$ (entries 3,4). PEGs are the PT catalysts of choice ${ }^{21}$; they are environmentally desisable because they are both non-toxic and inexpensive ${ }^{22,23}$. In complexing alkaline-metal cations, PEGs increase the basic strength of alkaline carbonates at a point that anionic nucleophiles (conjugate bases of the substrates) are produced in the reaction environment and methylated by DMC (see Scheme 1). The originated leaving group (methoxycarbonate anion, $\left.\mathrm{CH}_{3} \mathrm{OCOO}^{(-)}\right)$is not stable and rapidly decomposes into methanol and $\mathrm{CO}_{2}$; thus, the base can be used in catalytic amounts since the methoxide anion is regenerated. The methylation of arylacetonitriles proceeds with a very high monoalkyl selectivity (99\%) at complete conversion (entries $1,2)$. In particular, the procedure is used in the synthesis of the 2-(4-isobutylphenyl)propionitrile (entry 2 ), whose hydrolysis affords 2-(4-isobutylphenyl)propionic acid (Ibuprofen), a well-known anti-inflammatory drug $1 \mathrm{~b}$.

Table I also shows that under GL-PTC conditions, DMC is an excellent $\mathrm{N}$ - and $\mathrm{O}$-methylating agent; aniline selectively affords its mono- $N$-methyl derivative (entry 3 ), while phenol yields anisole quantitatively (entry 4$)^{11 \mathrm{~b}, 24}$.

GL-PTC conditions can be efficiently applied for the alkylation of compounds with a relatively high vapour pressure since they need to be vaporized into the reactor. Otherwise, high-temperature alkylations by light DAlkCs can also be run under batchwise conditions by reacting a mixture of the substrate, DAlkC and $\mathrm{K}_{2} \mathrm{CO}_{3}$ (a $1 / 18 / 2$ molar ratio is typically used) in a stainless-steel autoclave heated by an electric oven. The results for the alkylation of both arylacetonitriles and alkyl arylacetates with DMC or DEC under such

\begin{tabular}{|c|c|c|c|c|c|c|c|c|c|c|}
\hline \multirow[t]{2}{*}{ Entry } & \multicolumn{2}{|c|}{$\begin{array}{l}\text { Substrate } \\
\left(\mathrm{YCH}_{2} \mathrm{X}\right)\end{array}$} & \multirow[t]{2}{*}{$\begin{array}{c}\text { Alkylating } \\
\text { Agent }\end{array}$} & \multirow[t]{2}{*}{$\begin{array}{c}T \\
\left({ }^{\circ} \mathrm{C}\right)\end{array}$} & \multirow[t]{2}{*}{$\begin{array}{l}\text { Reaction } \\
\text { time (h) }\end{array}$} & \multirow[t]{2}{*}{$\begin{array}{c}\text { Conversion } \\
(\%)^{\mathrm{b}}\end{array}$} & \multicolumn{3}{|c|}{$\begin{array}{c}\text { Product } \\
\text { [YCH(R)X] }\end{array}$} & \multirow[t]{2}{*}{$\begin{array}{l}\text { Yield }^{\mathrm{c}} \\
(\%)\end{array}$} \\
\hline & $\mathbf{Y}$ & $\mathrm{X}$ & & & & & $\mathbf{Y}$ & $\mathbf{X}$ & $\mathbf{R}$ & \\
\hline 1 & $\mathrm{Ph}$ & $\mathrm{CN}$ & DMC & 180 & 3.75 & 100 & $\mathrm{Ph}$ & $\mathrm{CN}$ & $\mathrm{CH}_{3}$ & 90 \\
\hline 2 & $4-\mathrm{MeOC}_{6} \mathrm{H}_{4}$ & $\mathrm{CN}$ & DMC & 180 & 4.75 & 99 & 4- $\mathrm{MeOC}_{6} \mathrm{H}_{4}$ & $\mathrm{CN}$ & $\mathrm{CH}_{3}$ & 88 \\
\hline 3 & $2-\mathrm{MeC}_{6} \mathrm{H}_{4}$ & $\mathrm{CN}$ & DMC & 180 & 7.5 & 99 & $2-\mathrm{MeC}_{6} \mathrm{H}_{4}$ & $\mathrm{CN}$ & $\mathrm{CH}_{3}$ & 82 \\
\hline 4 & $4-\mathrm{ClC}_{6} \mathrm{H}_{4}$ & $\mathrm{CN}$ & DMC & 180 & 2.25 & 100 & $4-\mathrm{ClC}_{6} \mathrm{H}_{4}$ & $\mathrm{CN}$ & $\mathrm{CH}_{3}$ & 89 \\
\hline 5 & $3-\mathrm{MeO}_{2} \mathrm{CC}_{6} \mathrm{H}_{4}$ & $\mathrm{CN}$ & DMC & 180 & 8.0 & 100 & 3- $\mathrm{MeO}_{2} \mathrm{CC}_{6} \mathrm{H}_{4}$ & $\mathrm{CN}$ & $\mathrm{CH}_{3}$ & 91 \\
\hline 6 & $\mathbf{P h}$ & COOMe & DMC & 220 & 8.0 & 99 & Ph & COOMe & $\mathrm{CH}_{3}$ & 80 \\
\hline 7 & $2-\left(6-\mathrm{MeOC}_{10} \mathrm{H}_{6}\right)$ & COOMe & DMC & 220 & 6.0 & 100 & $2-\left(6-\mathrm{MeOC}_{10} \mathrm{H}_{6}\right)$ & COOMe & $\mathrm{CH}_{3}$ & 90 \\
\hline 8 & Ph & $\mathrm{CN}$ & DEC & 180 & 47.5 & 99 & $\mathbf{P h}$ & $\mathrm{CN}$ & $\mathrm{CH}_{2} \mathrm{CH}_{3}$ & 97 \\
\hline 9 & $\mathrm{Ph}$ & COOEt & DEC & 220 & 14.3 & 32 & $\mathrm{Ph}$ & COOEt & $\mathrm{CH}_{2} \mathrm{CH}_{3}$ & 12 \\
\hline 10 & $\mathrm{PhO}$ & $\mathrm{CN}$ & DMC & 190 & 32.0 & 100 & $\mathrm{PhO}$ & $\mathrm{CN}$ & $\mathrm{CH}_{3}$ & 62 \\
\hline 11 & $4-\mathrm{ClC}_{6} \mathrm{H}_{4} \mathrm{O}$ & $\mathrm{CN}$ & DMC & 180 & 41.0 & 100 & $4-\mathrm{ClC}_{6} \mathrm{H}_{4} \mathrm{O}$ & $\mathrm{CN}$ & $\mathrm{CH}_{3}$ & 52 \\
\hline 12 & $\mathrm{PhO}$ & COOMe & DMC & 190 & 40.0 & 99 & $\mathrm{PhO}$ & COOMe & $\mathrm{CH}_{3}$ & 80 \\
\hline 13 & $4-\mathrm{MeC}_{6} \mathrm{H}_{4} \mathrm{O}$ & COOMe & DMC & 190 & 70.0 & 100 & $4-\mathrm{MeC}_{6} \mathrm{H}_{4} \mathrm{O}$ & COOMe & $\mathrm{CH}_{3}$ & 83 \\
\hline 14 & $3-\mathrm{ClC}_{6} \mathrm{H}_{4} \mathrm{O}$ & COOMe & $\mathrm{DMC}$ & 190 & 26.0 & 100 & $3-\mathrm{ClC}_{6} \mathrm{H}_{4} \mathrm{O}$ & COOMe & $\mathrm{CH}_{3}$ & 82 \\
\hline
\end{tabular}

Table II Selective monoalkylation of methylene-active compounds $\mathrm{YCH}_{2} \mathrm{X}$ by dialkyl carbonates carried out under batchwise (autoclave) conditions ${ }^{\text {. }}$

"Entries 1-9 and 10-14: substrate, DAlkCs and $\mathrm{K}_{2} \mathrm{CO}_{3}$ in a $1 / 18 / 2$ and $1 / 30 / 2$ molar ratio, respectively. ${ }^{b}$ Conversions determined by GC.

c Yields based on distilled (entries $1-6$ and 10-14) or secrystallized (entry 7) products. Entry 8,9: GC-determined yields; in entry 9 , other products were $\mathrm{PhCH}(\mathrm{COOEt})_{2}(2 \%)$ and $\mathrm{PhC}(\mathrm{Et})(\mathrm{COOEt})_{2}(18 \%)$. 
<smiles>CC(C(=O)O)c1cccc(C(=O)c2ccccc2)c1</smiles>

Ketoprofen<smiles>COc1ccc2cc(C(C)C(=O)O)ccc2c1</smiles>

Naproxen

Figure 1. The non-steroidal anti-inflammatory agents Ketoprofen and Naproxen.

reaction conditions are reported in Table II (entries1-9). According to Eqn. 1, at temperatures ranging from 180 to $220^{\circ} \mathrm{C}$, all the reactions give the corresponding monoalkyl derivatives $[\mathrm{ArCH}(\mathrm{R}) \mathrm{CN}$ and $\mathrm{ArCH}(\mathrm{R}) \mathrm{COOR}$, respectively; $\mathrm{R}=\mathrm{CH}_{3}$ and $\mathrm{CH}_{2} \mathrm{CH}_{3}$ ] with a selectivity $>99 \%{ }^{13,14}$, as in GL-PTC reactions. This procedure can directly yield high-added value compounds as for examples, the 2-[3-(carboxymethyl)phenyl]propionitrile and the methyl 2-(6-methoxy2-naphthyl)propionate (entries 5 and 7, Table II) which are intermediates for the synthesis of the analgesics Ketoprofen and Naproxen, respectively (Figure 1 ).

Table II shows also the results for the batchwise methylation of (aryloxy)acetonitriles and methyl (aryloxy)acetates by DMC; although these reactions generally require longer reaction times than those of the arylacetic-acid derivatives, they proceed with a comparably high monomethyl selectivity (entries $10-14)^{15}$. However, in the case of (aryloxy)acetonitriles $\left(\mathrm{ArOCH}{ }_{2} \mathrm{CN}\right)$, the yields are lower $(50-60 \%$; entries 10,11$)$ because of the concomitant formation of the corresponding anisoles $\left(\mathrm{ArOCH}_{3}\right)$. This is probably due to a nucleophilic displacement on the $\mathrm{ArOCH}_{2} \mathrm{CN}$ (by a nucleophile present in the reaction mixture, i.e. $\mathrm{CH}_{3} \mathrm{O}^{(-)}, \mathrm{CO}_{3}^{(2-)}$, etc.) giving a phenoxide leaving group ( $\mathrm{ArO}^{(-)}$) which rapidly reacts with DMC to yield the corresponding anisole through a $B_{\mathrm{Al}} 2$ mechanism.

All the reported reactions in Table II use DAlkCs in a large excess (20-30 molar with respect to the substrate), thus acting as the alkylating agents and the solvents. No improvements in the reaction rate are observed using apolar (cyclohexane), protic polar (methanol) or aprotic polar (DMF) compounds as solvents or co-solvents.

These reactions produce no hazardous wastes. Conversely, from the alkylations with dialkyl sulfates or alkyl chlorides a base is consumed as a reagent and therefore, stoichiometric quantities of inorganic salts are produced; in the reactions of DAlkCs the base is catalytic since the acidity is removed as $\mathrm{CO}_{2}$ which does not involve disposal problems. Moreover, the co-product alcohol can be easily recycled.

At high temperatures $\left(150-180^{\circ} \mathrm{C}\right)$, the dibenzyl carbonate (DBzlC) is also an efficient benzylating agent of both methylene-active compounds and phenol ${ }^{16}$, and the high boiling point of $\mathrm{DBzlC}\left(197^{\circ} \mathrm{C} / 12 \mathrm{~mm}\right)$ allows the benzylations to be performed batchwise at atmospheric pressure. In a typical reaction, a mixture of the substrate, $\mathrm{DBzlC}$ and $\mathrm{K}_{2} \mathrm{CO}_{3}$ [in a $1 /(1.1 \div 1.5) / 2$ molar ratio, respectively] reacts in a refluxing high-boiling solvent, the best solvents being $N, N$-dimethyl- and $N, N$-diethyl-formamides (DMF and DEF, respectively). Results are reported in Table III.
Although the alkylations of methylene-active compounds by alkyl halides in the presence of $\mathrm{K}_{2} \mathrm{CO}_{3}$ and DMF solvent have been extensively reported, a high monoalkyl selectivity is elusive when reactive halides (e.g. benzyl halides) are involved ${ }^{25,26}$. Instead, the use of DBzlC as alkylating agent allows the benzylation of both phenylacetonitrile and benzyl phenylacetate to proceed with a monobenzyl selectivity of 99\% at complete conversion (entries 1,2). Also, O-benzylation of phenol by DBzlC gives benzyl phenyl ether in a good yield (entry 3 ).

As a general trend related to all the alkylations of $\mathrm{CH}_{2}$-acidic compounds by DAlkCs, it can be noted that aryl- and (aryloxy)acetonitriles are alkylated more rapidly than the corresponding esters, [alkyl-, aryl- and (aryloxy)acetates], these latter generally requiring higher reaction temperatures and/or longer reaction times (see Tables II and III). An explanation is that the formation of the carbanion $\mathrm{YCH}^{(-)} \mathrm{X}$ is easier for nitriles $(X=C N)$ than for esters $(X=C O O R)$, the former having a poor electron availability on the methylenic carbon which allow them to be both more acidic and electrophilic in character.

\section{Reaction mechanism}

The singular monoalkyl selectivity in the alkylation of methylene-active derivatives by DAlkCs has been explained through two consecutive and very selective reactions involving two reaction intermediates, namely an alkoxycarbonylated [YCH(COOR)X; $\mathrm{R}=\mathrm{Me}, \mathrm{Et}, \mathrm{Bzl}]$ and an alkyl-alkoxycarbonylated [YC(R)(COOR)X] species, both actually observed during the reactions ${ }^{14-16}$. Scheme 1 shows the proposed mechanism.

According to a $B_{\mathrm{Ac}} 2$ mechanism, the first generated $\mathrm{YCH}^{(-)} \mathrm{X}$ anion reacts only with the acyl carbon of the DAlkC and not with the alkyl one, yielding the alkoxycarbonylated intermediate $\mathrm{YCH}(\mathrm{COOR}) \mathrm{X}$. The corresponding anion, $\mathrm{YC}^{(-)}(\mathrm{COOR}) \mathrm{X}$, is then alkylated through its reaction with the alkyl carbon of the DAlkC, thus giving the alkyl-alkoxycarbonylated compound, YC(R)(COOR)X, via a $B_{\mathrm{Al}} 2$ mechanism. Finally, an equilibrium de-alkoxycarbonylation reaction affords the product $\mathrm{YCH}(\mathrm{R}) \mathrm{X}$. In this case, the attack on the acyl carbon by the $\mathrm{YC}^{(-)}(\mathrm{COOR}) \mathrm{X}$ anion producing the possible intermediate $\mathrm{YC}(\mathrm{COOR})_{2} \mathrm{X}$, does not effect the selectivity, this being an equilibrium reaction.

The high selectivity obtained is actually a result of the double reactivity that DAlkCs may exhibit, acting firstly as alkoxy-

Table III Benzylation of different substrates by dibenzyl carbonate ".

\begin{tabular}{|c|c|c|c|c|c|c|}
\hline Entry & Substrate & Solvent & $\begin{array}{l}\text { Reaction } \\
\text { time (h) }\end{array}$ & $\begin{array}{c}T \\
\left({ }^{\circ} \mathrm{C}\right)\end{array}$ & $\begin{array}{c}\text { Conversion }{ }^{\mathrm{b}} \\
(\%)\end{array}$ & 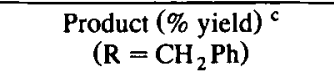 \\
\hline $\begin{array}{l}1 \\
2 \\
3\end{array}$ & $\begin{array}{c}\mathrm{PhCH}_{2} \mathrm{CN} \\
\mathrm{PhCH}_{2} \mathrm{COOCH}_{2} \mathrm{Ph} \\
\mathrm{PhOH}^{2}\end{array}$ & $\begin{array}{l}\text { DMF } \\
\text { DEF } \\
\text { DMF }\end{array}$ & $\begin{array}{l}6.0 \\
4.5 \\
2.0\end{array}$ & $\begin{array}{l}155 \\
177 \\
155\end{array}$ & $\begin{array}{l}90 \\
92 \\
94\end{array}$ & $\begin{array}{c}\mathrm{PhCH}(\mathrm{R}) \mathrm{CN}(82)^{\mathrm{d}} \\
\left.\mathrm{PhCH}(\mathrm{R}) \mathrm{COOCH} \mathrm{Ph}_{2} \mathrm{Ph}\right)^{\mathrm{d}} \\
\mathrm{PhOR}(80)^{\mathrm{e}}\end{array}$ \\
\hline
\end{tabular}

a Entries 1 and 3: substrate, DBzlC and $\mathrm{K}_{2} \mathrm{CO}_{3}$ in a 1/1,1/2 molar ratio, respectively. Entry 2: substrate, DBzlC and $\mathrm{K}_{2} \mathrm{CO}_{3}$ in a $1 / 1,5 / 2$ molar ratio.

${ }^{b}$ Determined by GC. ${ }^{c}$ Yields based on isolated products. ${ }^{\mathrm{d}}$ Starting from $2.5 \mathrm{~g}$ of substrate. ${ }^{e}$ Starting from $2.0 \mathrm{~g}$ of substrate. 


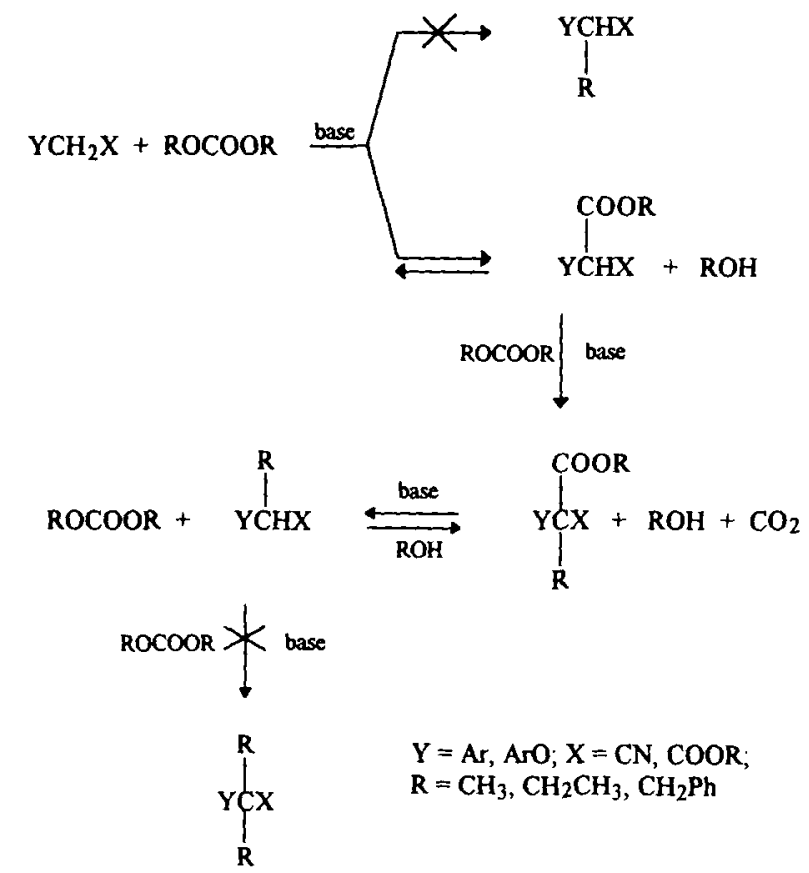

Scheme 1. The reaction mechanism for the mono-C-alkylations of methylene-active compounds by dialkyl carbonates.

carbonylating and then as alkylating agents. The reason why the reaction involves alkoxycarbonylated intermediates, and not direct methylation, is as yet unclear.

\section{Conclusions}

The monoalkylation of methylene-active compounds with DAlkCs represents a new, environmentally benign reaction which involves the use of non-toxic alkylating agents (DAlkCs) in a waste-free process. The method opens new perspectives for the development of these intrinsically safer compounds, either as alkylating agents and/or as easily biodegradable solvents. Moreover, the procedure actually prevents pollution at source; in addition to the absence of both organic and inorganic wastes during alkylation, the new technology for the DMC synthesis (Eqn. 1) also avoids chlorinated intermediates; non-toxic waste disposal in the overall reaction is required and the process can be considered intrinsically safe.

\section{Experimental}

\section{General}

All compounds were ACS-grade and were employed without further purification. Melting points were determined on a Buchi 535 melting-point apparatus and are uncorrected. ${ }^{1}$ H-NMR spectra were recorded on a Varian spectrometer $(400 \mathrm{MHz})$ using $\mathrm{CDCl}_{3}$ with TMS as the internal standard. GC (gas chromatography) analyses were performed on a Varian GC 3300 using a fused-silica capillary column $(30 \mathrm{~m} \times 0.25 \mathrm{~mm})$ with DB5 as liquid phase (film thickness $0.25 \mathrm{~mm}$ ). GC/MS analyses were performed on a HP 5971 mass detector coupled to a HP 5890 gas chromatograph fitted with a $30 \mathrm{~m} \times 0.25 \mathrm{~mm}$ DB5 capillary column.

Reactions carried out under continuous-flow conditions

All reactions were carried out at atmospheric pressure and $180^{\circ} \mathrm{C}$. In the case of methylations of arylacetonitriles by DMC (entries 1,2, Table I), the catalytic bed was obtained by dissolving PEG $6000(5 \mathrm{~g})$ and $\mathrm{K}_{2} \mathrm{CO}_{3}$ $(5 \mathrm{~g})$ in de-ionized water, and pouring the solution over corundum spheres $\left(\alpha-\mathrm{Al}_{2} \mathrm{O}_{3}, 90 \mathrm{~g}\right)$. The water was removed by totary evaporation. After drying the coated spheres in an oven $\left(130^{\circ} \mathrm{C}\right)$ overnight, they were fitted into a glass cylindrical reactor $(20 \times 3 \mathrm{~cm}$; length $\times$ diameter $)$.
The liquid mixture of the reagents $(8.0 \mathrm{ml} / \mathrm{h} ; \mathrm{DMC}$ and substrate in a $4 / 1$ molar ratio, respectively) was then introduced at the inlet of the reactor thermostatted at the reaction temperature, and products were recovered by simple condensation at the outlet.

In the case of methylations of aniline and phenol (entries 3,4, Table I), the reactions proceeded according to the same procedure (flow rate $24 \mathrm{ml}$ $/ \mathrm{h} ; \mathrm{DMC}$ and substrate in a $4 / 1$ molar ratio, respectively), but the catalytic bed was of PEG $6000(5 \mathrm{~g})$ directly supported on $\mathrm{K}_{2} \mathrm{CO}_{3}(95 \mathrm{~g})$.

Reactions carried out in an autoclave; general procedure

All reactions were carried out by loading a mixture of the dialkyl carbonate (DMC or DEC), the substrate and the base $\left(\mathrm{K}_{2} \mathrm{CO}_{3}\right)$ into a stainless-steel autoclave (internal volume $250 \mathrm{ml}$ ) in the reported molar ratio (see Table II). The autoclave was equipped with a purging valve, through which, at room temperature, air was removed before each reaction by purging with a nitrogen stream. The autoclave was heated in an electrical oven to the desired temperature $\left(180-220^{\circ} \mathrm{C}\right.$; the temperature was checked by a thermocouple dipped into the teaction mixture), while the reaction mixture was kept under magnetic stirring. A needle valve was fixed onto the autoclave head, and connected to a $\frac{1}{8}$-inch stainlesssteel suction pipe immersed into the reaction mixture, by which samples were extracted and analysed by GC during the course of the reactions. Under such conditions, autogenic pressure ranged from 6 to 20 bar. All the monoalkylated products were purified by distillation under reduced pressure, except for Naproxen (entry 7, Table II) which was recrystallized.

Benzylation reactions

The reactions were performed at atmospheric pressure by loading a 3-necked, round-bottomed flask with the mixture of substrate, DBzIC, $\mathrm{K}_{2} \mathrm{CO}_{3}$ and solvent (DMF or DEF) in the reported molar ratio (see Table III). The flask was equipped with a condenser, a cock and a glass screw-capped tube (fitted with a rubber silicon septum) used for sample withdrawal. Before heating, a nitrogen stream was flowed into the flask and kept for the whole course of the reaction. The reaction mixture was then magnetically stirted and heated in an oil bath to the desired temperature. After monobenzylations were completed, the co-product benzyl alcohol was distilled off under reduced pressure and the products purified by recrystallization (entries 1,3 , Table III) or gravity column chromatography (entry 2, Table III).

The purity of the products was checked by GC, GC/MS and NMR. The spectroscopic ( ${ }^{1} \mathrm{H}-\mathrm{NMR}$ and GC/MS spectra) and physical properties of all the monoalkylated derivatives have been already reported ${ }^{14-16}$.

\section{References}

1 W. Carruthers, "Some Modern Synthetic Methods of Organic Synthesis", 3rd Ed..Cambridge University Press, Cambridge (UK), 1989.

2 C.M. Starks, C. Liotta, "Phase-Transfer Catalysis, Principles and Techniques", Academic Press, Inc., New York, 1976; Chapter 5, pp. 170-196.

3 E.V. Dehmlov, S.S. Dehmlov, "Phase-Transfer Catalysis", Verlag Chemie, Weinheim, 1983, Chapter 3, pp. 123-140.

4 J.P. Rieu, A. Boucherle, H. Cousse, G. Mouzin, Tetrahedron 42, 4095 (1986).

5 R.L. Buchanan, V. Sprancmanis, R.A. Partyka, J. Med. Chem. 12, 1001 (1969).

6 J. Lehmann, F. Latanowicz, Arch. Pharm. 319, 278 (1986)

7 G. Bettoni, S. Ferorelli, F. Loiodice, N. Tangari, V. Tortorella, F. Gasparrini, D. Misiti, C. Villani, Chirality 4, 193 (1992).

8 Z. Ejmocki, Z. Eckstein, Rocz. Chem. (Engl.) 45, 345 (1971); Chem. Abstr. 75, 63348p (1971).

9 B. Cambou, A.M. Klibanov, Biotechnol. Bioeng. 26, 1449 (1984).

10 R. Chênevert, L. D'Astous, Can. J. Chem. 66, 1219 (1988).

11a $P$. Tundo, G. Moraglio, F. Trotta, Ind. Eng. Chem. Res. 28, 881 (1989);

b P. Tundo, G. Moraglio, F. Trotta, J. Chem. Soc., Perkin Trans. I, 1070 (1989).

12 P. Tundo, "Continuous Flow Methods in Organic Synthesys", $E$. Horwood (Publisher), Chichester (UK), 1991.

13 P. Loosen, P. Tundo, M. Selva, US Pat. 5278533 (1994).

14 M. Selva, C.A. Marques, P. Tundo, J. Chem. Soc., Perkin Trans. I, 1323 (1994).

15 A. Bomben, C.A. Marques, M. Selva, P. Tundo, Tetrahedron No. 42 51, pp. 11573 (1995)

16 M. Selva, C.A. Marques, P. Tundo, J. Chem. Soc., Perkin Trans. I, 1889 (1995). 
17 U. Romano, R. Tesei, M. Massi Mauri, P. Rebora, Ind. Eng. Prod. Res. Dev. 19, 396 (1980).

18 A. Matsumoto, K. Takashima, M. Oiwa, Bull. Chem. Soc. Jap. 42, 1959 (1969).

19 A.G. Shaikh, S. Sivaram, Ind. Eng. Chem. Res. 31, 1167 (1992)

20 M.L. Quesada, R.H. Schlessinger, J. Org. Chem. 43, 346 (1978).

21 P. Tundo, M. Selva, Chemtech 25(5), 31 (1995).
22 D. Lee, V. Chang, J. Org. Chem. 43, 1532 (1978).

23 J.M. Harris, N.H. Hudley, T.G. Shannon, E.C. Struck, J. Org. Chem. 47, 4789 (1982).

24 P. Tundo, F. Trotta, G. Moraglio, J. Org. Chem. 52, 1300 (1987).

25 D.A. White, Synth. Commun. 7, 559 (1977).

26 N.N. Sukhanov, L.N. Trappel, V.P. Chetverkov, LA. Yanouskaya, Zh. Org. Khim. 21, 2503 (1985); Chem. Abstr. 105, 225743 f (1986). 